\title{
Acute intensive insulin therapy exacerbates diabetic blood-retinal barrier breakdown via hypoxia-inducible factor-1 $\alpha$ and VEGF
}

\author{
Vassiliki Poulaki, ${ }^{1,2}$ Wenying Qin, ${ }^{1,2}$ Antonia M. Joussen, ${ }^{1,2,3}$ Peter Hurlbut, ${ }^{1}$ \\ Stanley J. Wiegand, ${ }^{4}$ John Rudge, ${ }^{4}$ George D. Yancopoulos, ${ }^{4}$ and Anthony P. Adamis ${ }^{1,2}$ \\ ${ }^{1}$ Laboratory of Surgical Research, Children's Hospital, Harvard Medical School, Boston, Massachusetts, USA \\ ${ }^{2}$ Department of Ophthalmology, Massachusetts Eye and Ear Infirmary, Harvard Medical School, Boston, Massachusetts, USA \\ ${ }^{3}$ Department of Vitreoretinal Surgery, Center of Ophthalmology, University of Cologne, Cologne, Germany \\ ${ }^{4}$ Regeneron Pharmaceuticals Inc., Tarrytown, New York, USA
}

Address correspondence to: Anthony P. Adamis, Massachusetts Eye and Ear Infirmary,

243 Charles Street, Boston, Massachusetts 02114, USA.

Phone: (617) 573-6387; Fax: (617) 573-3078; E-mail: tony_adamis@meei.harvard.edu.

Vassiliki Poulaki and Wenying Qin contributed equally to this work.

Received for publication July 16, 2001, and accepted in revised form January 28, 2002.

Acute intensive insulin therapy is an independent risk factor for diabetic retinopathy. Here we demonstrate that acute intensive insulin therapy markedly increases VEGF mRNA and protein levels in the retinae of diabetic rats. Retinal nuclear extracts from insulin-treated rats contain higher hypoxiainducible factor- $1 \alpha$ (HIF-1 $\alpha$ ) levels and demonstrate increased HIF- $1 \alpha$-dependent binding to hypoxiaresponsive elements in the VEGF promoter. Blood-retinal barrier breakdown is markedly increased with acute intensive insulin therapy but can be reversed by treating animals with a fusion protein containing a soluble form of the VEGF receptor Flt; a control fusion protein has no such protective effect. The insulin-induced retinal HIF-1 $\alpha$ and VEGF increases and the related blood-retinal barrier breakdown are suppressed by inhibitors of $\mathrm{p} 38$ mitogen-activated protein kinase (MAPK) and phosphatidylinositol (PI) 3-kinase, but not inhibitors of $\mathrm{p} 42 / \mathrm{p} 44 \mathrm{MAPK}$ or protein kinase C. Taken together, these findings indicate that acute intensive insulin therapy produces a transient worsening of diabetic blood-retinal barrier breakdown via an HIF-1 $\alpha$-mediated increase in retinal VEGF expression. Insulin-induced VEGF expression requires $\mathrm{P} 38$ MAPK and PI 3-kinase, whereas hyperglycemia-induced VEGF expression is HIF-1 $\alpha$-independent and requires PKC and p42/p44 MAPK. To our knowledge, these data are the first to identify a specific mechanism for the transient worsening of diabetic retinopathy, specifically blood-retinal barrier breakdown, that follows the institution of intensive insulin therapy.

J. Clin. Invest. 109:805-815 (2002). DOI:10.1172/JCI200213776.

\section{Introduction}

Clinical trials have demonstrated that acute intensive insulin therapy causes a transient worsening of diabetic retinopathy in type 1 diabetes patients (1-5). The worsening results, in part, from hard exudates and macular edema - pathologies that are manifestations of blood-retinal barrier breakdown. However, continued intensive insulin therapy eventually leads to a marked reduction in the risk of diabetic retinopathy onset and progression $(5,6)$.

Patients with type 2 diabetes converting to acute intensive insulin therapy also show a marked increase in retinopathy risk when compared with patients on oral hypoglycemic drugs. The effect is insulin dose-dependent (7), and the progression of retinopathy is seen at multiple levels, ranging from no retinopathy to moderate background retinopathy (8). While hyperglycemia is an independent risk factor, the change from oral hypoglycemic drugs to insulin is associated with a $100 \%$ increased risk of retinopathy progression and a threefold increased risk of visual impairment (9). As in type 1 diabetes, long-term intensive therapy (more than 6 years) eventually reduces the risk of retinopathy development and progression (10). The mechanisms underlying the early deterioration of retinopathy following the institution of acute intensive insulin therapy remain unknown.

VEGF is a family of angiogenic and vascular permeability-enhancing peptides derived from alternatively spliced mRNAs. VEGF bioactivity is primarily mediated via two high-affinity cognate receptors, kinase insert domain receptor (KDR)/Flk-1 and Flt-1 $(11,12)$. Preclinical and clinical studies have shown that VEGF is operative in the pathogenesis of both background and proliferative diabetic retinopathy (13-15). Intraocular VEGF levels are increased in diabetic human eyes with blood-retinal barrier breakdown and neovascularization (13, 15-17), and notably, the specific inhibition of VEGF bioactivity prevents neovascularization and blood-retinal barrier breakdown in various relevant animal models (14-18). 
Insulin signaling begins with activation of the insulin receptor kinase via autophosphorylation. Several cytoplasmic proteins bind to the activated receptor and are subsequently phosphorylated at their tyrosine residues $(19,20)$. These events lead to multiple signaling pathways, resulting in the activation of various transcription factors, an important one being hypoxia-inducible factor- $1 \alpha$ (HIF- $1 \alpha)$. HIF- $1 \alpha$ is a basic helix-loop-helix-per-ARNT-sim (bHLH-PAS) transcription factor that is induced by hypoxia and forms a functional heterodimer with the bHLH-PAS protein aryl hydrocarbon nuclear translocator (ARNT), or HIF-1 $\beta$ (21). The highly specific activation of HIF- $1 \alpha$ is mediated by the $\alpha$ subunit, whereas the $\beta$ subunit is a nonselective heterodimerization partner for a variety of bHLH proteins (22). It was recently reported that insulin transcriptionally upregulates VEGF in vitro via the HIF-1 $\alpha /$ ARNT heterodimer, which binds to two hypoxia-responsive elements (HREs) in the VEGF promoter $(22,23)$.

The effect of acute intensive insulin therapy on VEGF gene expression and regulation in vivo, and its biological significance with respect to diabetic retinopathy and blood-retinal barrier breakdown, is not currently known. We hypothesized that acute intensive insulin treatment, via HIF-1 $\alpha$, increases retinal VEGF expression, which worsens blood-retinal barrier breakdown in diabetes. Further, the signaling pathways for insulininduced VEGF expression were hypothesized to differ from those mediating hyperglycemia-induced VEGF expression. These hypotheses were directly tested in a relevant rat model of diabetic retinopathy.

\section{Methods}

Cell culture and signal pathway inbibitors. Human retinal pigment epithelial (RPE) cells (passage 2) were used for the in vitro studies (generous gift of B. Kirchhof, Department of Vitreoretinal Surgery, Center for Ophthalmology and Center for Molecular Medicine [ZMMK], University of Cologne, Cologne, Germany). RPE cells have accurately predicted the in vivo regulation of the retinal VEGF gene expression in previous studies (24). RPE cells were maintained in DMEM (Sigma Diagnostics, St. Louis, Missouri, USA) containing 10\% heat-inactivated FCS (HyClone Laboratories, Logan, Utah, USA) and $100 \mathrm{U} / \mathrm{ml}$ penicillin, 100 $\mathrm{mg} / \mathrm{ml}$ streptomycin, and $2 \mathrm{mM}$ L-glutamine. Cells were plated into six-well plastic dishes and used for experiments when they reached $80-100 \%$ confluence. Fresh serum-free media were placed on the cells 12 hours before experiments. The following inhibitors were used: for phosphatidylinositol (PI) 3-kinase inhibition, wortmannin and LY294002 (25); for p42/p44 mitogen-activated protein kinase (MAPK) inhibition, U0126 and PD169316 (26); for p38 inhibition, SB202190 and SB203580 (27); for protein kinase C (PKC) inhibition, the peptide C2-4, Ro-31-7549, and Ro-32-0432 (28, 29) (all from Calbiochem-Novabiochem Corp., San Diego, California, USA). The inhibitors were added 1 hour before incubation with $10 \mathrm{nM}$ insulin, at a concentration of $50 \mu \mathrm{M}$, except wortmannin, which was used at a concentration of 50 $\mathrm{nM}$. The incubation time was 12 hours. For the hyperglycemia experiments, the cells were incubated for 2 days in $25 \mathrm{mM}$ glucose, or $25 \mathrm{mM}$ mannose, with or without the kinase inhibitors. Conditioned media were assayed as previously described (30) to assess the concentration of the secreted VEGF. Each condition was prepared in triplicate, and the experiments were performed at least three times with reproducible results. The results within the same class of inhibitors were similar; therefore the results were combined. The mean \pm SD of these experiments is shown.

Animals and experimental diabetes. All animal experiments followed Association for Research in Vision and Ophthalmology guidelines and were approved by the animal care and use committees of the Children's Hospital and the Massachusetts Eye and Ear Infirmary. Male Long-Evans rats weighing approximately $200 \mathrm{~g}$ (Charles River Laboratories, Wilmington, Massachusetts, USA) received a single $60-\mathrm{mg} / \mathrm{kg}$ injection of streptozotocin (Sigma Chemical Co., St. Louis, Missouri, USA) in $10 \mathrm{mM}$ citrate buffer, $\mathrm{pH} 4.5$, following an overnight fast. Control nondiabetic rats received injections of citrate buffer alone. Twenty-four hours later, rats with blood glucose levels greater than 250 $\mathrm{mg} / \mathrm{dl}$ were deemed diabetic. The animals were then assigned to their various treatment groups in a randomized fashion. All rat experiments were performed 8 days after the induction of diabetes. All animals were fed standard laboratory chow and were allowed free access to food and water in an air-conditioned room with a 12-hour light/dark cycle. On the day of the experiment, and after the induction of anesthesia, all rats were weighed before sacrifice.

Implantation of the osmotic pumps. Osmotic pumps permit controlled delivery and steady-state drug levels in the circulation. One day following diabetes induction, the rats were deeply anesthetized and osmotic pumps (Alzet osmotic pumps; Durect Corp., Cupertino, California, USA) containing either vehicle or the inhibitors described below were inserted into the peritoneal space. Specifically, the abdominal area was shaved, scrubbed with Betadine, and wiped with alcohol. A $15-\mathrm{mm}$ incision was made in the midline through the skin and muscles to enter the peritoneal cavity. An osmotic pump (Durect Corp.) was inserted through this opening into the peritoneal space. The pump was free-floating within the abdomen and measured 1.3 $\mathrm{cm} \times 6 \mathrm{~mm}$. The wound was closed with a single suture in the muscle and skin layers. The following inhibitors were used: for PI 3-kinase inhibition, wortmannin and LY294002 (25); for p42/p44 MAPK inhibition, U0126 and PD169316 (26); for p38 inhibition, SB202190 and SB203580 (27); for PKC inhibition, the peptide C2-4, Ro-31-7549, and Ro-32-0432 $(28,29)$ (CalbiochemNovabiochem Corp.). Only one inhibitor was added per pump, i.e., they were not combined. The results 
within the same class of inhibitors were similar; therefore the results were combined. The mean \pm SD of these experiments is shown.

Insertion of the insulin pellet. One day after the diabetes induction, the rats were anesthetized and had two controlled-release insulin implants (LinShin Canada Inc., Toronto, Ontario, Canada) placed in the subcutaneous space of the abdomen. The implants release $2 \mathrm{U}$ of insulin per 24 hours for a period of 40 days. The control implants were identical in size but were devoid of insulin. All experiments were performed 1 week after the insertion of the implants. Blood glucose was monitored every day following insertion. After cleaning the shaved skin with $10 \%$ povidone-iodine, a 16 -gauge disposable hypodermic needle was placed inside a small pinch of skin overlying the abdomen, and then rapidly withdrawn. A sterile trocar was then pushed $2 \mathrm{~cm}$ through the skin orifice. The insulin or control implants were inserted through the trocar with a stylet. The skin was pinched over the implant, and the trocar and stylet were removed. The contraction of the skin defect obviated the requirement for sutures or clips.

VEGF TrapA 40 reagent. VEGF TrapA 40 and IL-6 receptor $/ F_{c}$ control (inactive IL-6R Trap) were synthesized by Regeneron Pharmaceuticals Inc. (Tarrytown, New York, USA). VEGF TrapA 40 was made from Ig repeats $1-3$ of the extracellular domain of human Flt- 1 fused to the $F_{c}$ portion of human IgG. The protein was expressed in Chinese hamster ovary $(\mathrm{CHO})$ cells and purified via protein A affinity chromatography, followed by size exclusion chromatography. The recombinant VEGF $\mathrm{TrapA}_{40}$ was then chemically modified to improve the pharmacokinetic profile of the parent molecule, without affecting its ability to bind VEGF with high affinity (J. Rudge et al., unpublished data). The purity of the modified recombinant protein was determined to be greater than $95 \%$ by Coomassie-stained SDS-PAGE. The protein was filter-sterilized and stored at 3.25 $\mathrm{mg} / \mathrm{ml}$ in PBS, $\mathrm{pH} 7.2$, containing $5 \%$ glycerol at $-20^{\circ} \mathrm{C}$.

Inactive IL-6R Trap was similarly generated, using the extracellular domain of human IL-6R $\alpha$ (the low-affinity IL- 6 receptor) fused to the $F_{c}$ domain of human $\mathrm{IgG}_{1}$. Inactive IL-6R Trap only binds human IL- 6 with low affinity and does not bind to rat IL-6. Like VEGF TrapA $\mathrm{A}_{40}$, it was $\mathrm{CHO}$ cell-derived and purified over protein A and was more than 95\% pure on Coomassiestained gels. It was filter-sterilized and stored at 3.25 $\mathrm{mg} / \mathrm{ml}$ in PBS, $\mathrm{pH} 7.2$, containing $5 \%$ glycerol at $-20^{\circ} \mathrm{C}$. Confirmed diabetic rats received single $25-\mathrm{mg} / \mathrm{kg}$ intraperitoneal injections of either VEGF TrapA 40 or Inactive IL-6R Trap 24 hours prior to analysis.

Measurement of blood-retinal barrier breakdown using Evans blue. Retinal blood vessel permeability was quantified using Evans blue dye, which noncovalently binds to plasma albumin in the bloodstream (31). Evans blue dye (Sigma Chemical Co.) was dissolved in normal saline $(30 \mathrm{mg} / \mathrm{ml})$, sonicated for 5 minutes, and filtered through a $5-\mu \mathrm{m}$ filter. A heparinized PE50 catheter was inserted in the femoral artery. Under deep anesthesia,
Evans blue $(30 \mathrm{mg} / \mathrm{kg})$ was injected through a jugular vein catheter for 10 seconds. Blood was withdrawn through the femoral catheter into a heparinized syringe every 15 minutes, for a total of 120 minutes. After the dye circulated for 120 minutes, the chest cavity was opened and the left heart ventricle was cannulated. Each rat was perfused with citrate-buffered 1\% paraformaldehyde $\left(37^{\circ} \mathrm{C}\right)$ for 2 minutes to clear the dye, with the physiological pressure kept at $100 \mathrm{mmHg}$. Immediately following perfusion, the eyes were enucleated and the retinae were carefully dissected away under an operating microscope. The weight of each retina was measured after thorough drying in a SpeedVac (Savant Instruments Inc., Holbrook, New York, USA). Albumin leakage into the retinal tissue was estimated via the measurement of extravasated Evans blue dye. Evans blue was extracted by incubating each retina in $0.3 \mathrm{ml}$ formamide for 18 hours at $70^{\circ} \mathrm{C}$. The extract was filtered through a 30,000 -molecular weight filter at a speed of $3,000 \mathrm{~g}$ for 45 minutes at $4^{\circ} \mathrm{C}$. The absorbance of the filtrate was measured with a spectrophotometer at $620 \mathrm{~nm}$ absorbance maximum and $720 \mathrm{~nm}$ absorbance minimum for Evans blue in formamide. The arterial blood samples were centrifuged at $10,000 \mathrm{~g}$ for 20 minutes at $4^{\circ} \mathrm{C}$, and the concentration of the dye in the supernatants was calculated from a standard curve of Evans blue in formamide. The concentration of dye in the extracts was calculated from a standard curve of Evans blue in formamide and normalized to the dry retinal weight and the time-averaged concentration of Evans blue in the plasma (32).

Ribonuclease protection assay. Rat retinae were gently dissected free, cut at the optic disc following enucleation, and immediately frozen in liquid nitrogen. Total RNA was isolated according to the acid guanidinium thiocyanate-phenol-chloroform extraction method. A segment of rat VEGF cDNA containing exons 4-7 and a portion of exon 8 was prepared by RT-PCR. An automated DNA sequencer verified the sequence of the cloned cDNA. Nucleotide antisense riboprobes were prepared by in vitro transcription (Promega Corp., Madison, Wisconsin, USA) of linearized plasmid DNA with T7 RNA polymerase in the presence of [ $\left.{ }^{32} \mathrm{P}\right] \mathrm{dUTP}$. Twenty micrograms of total cellular RNA was used for the ribonuclease protection assay (RPA). All samples were simultaneously hybridized with an $18 \mathrm{~S}$ riboprobe (Ambion Inc., Austin, Texas, USA) to normalize for variations in loading and recovery of RNA. The protected fragments were separated on a gel of 5\% acrylamide, $8 \mathrm{M}$ urea, $1 \times$ Tris-borate-EDTA, and quantified with a PhosphorImager (Molecular Dynamics, Sunnyvale, California, USA). All signals were within the linear range of quantitation.

VEGF ELISA. Each retina was placed in $200 \mu \mathrm{l}$ lysis buffer $(20 \mathrm{mM}$ imidazole $\mathrm{HCl}, 10 \mathrm{mM} \mathrm{KCl}, 1 \mathrm{mM}$ $\mathrm{MgCl}_{2}, 10 \mathrm{mM}$ EGTA, $1 \%$ Triton, $10 \mathrm{mM} \mathrm{NaF}, 1 \mathrm{mM}$ Na molybdate, 1 mM EDTA pH 6.8) supplemented with a protease inhibitor cocktail (Roche Molecular Biochemicals Inc., Indianapolis, Indiana, USA), followed by 
sonication. The lysate was cleared of debris by centrifugation at $12,000 \mathrm{~g}$ for 15 minutes $\left(4^{\circ} \mathrm{C}\right)$, and the supernatant was assayed. Total protein was determined using the bicinchoninic assay (BCA protein assay kit; Pierce Co., Rockford, Illinois, USA). Supernatant VEGF levels (from retina or RPE cells) were determined using a sandwich ELISA according to the manufacturer's instructions (R\&D Systems Inc., Minneapolis, Minnesota, USA) and normalized to total protein.

Preparation of nuclear extracts. Pooled retinae from nondiabetic, control-treated, and insulin-treated diabetic rats were isolated as previously described and homogenized with a mechanical homogenizer in five pellet volumes of buffer A (20 mM Tris [pH 7.6], $10 \mathrm{mM} \mathrm{KCl}$, $0.2 \mathrm{mM}$ EDTA, $20 \%$ [by volume] glycerol, $1.5 \mathrm{mM}$ $\mathrm{MgCl}_{2}, 2 \mathrm{mM}$ DTT, $1 \mathrm{mM} \mathrm{Na} \mathrm{VO}_{4}$, and protease inhibitors; Roche Molecular Biochemicals Inc.). The nuclei were pelleted $(2500 \mathrm{~g}, 10$ minutes $)$ and resuspended in two pellet volumes of buffer $B$ (identical to buffer A except that $\mathrm{KCl}$ was increased to $0.42 \mathrm{M}$ ). Nuclear debris was removed by centrifugation $(15000$ g, 20 minutes), and the supernatant was dialyzed against one exchange of buffer $Z(20 \mathrm{mM}$ Tris- $\mathrm{HCl}[\mathrm{pH}$ 7.8 ], $0.1 \mathrm{M} \mathrm{KCl}, 0.2 \mathrm{mM}$ EDTA, $20 \%$ glycerol) for at least 3 hours at $4^{\circ} \mathrm{C}$ with Dialyze $Z$ cassettes (Pierce Co.). The protein concentration was measured using a Pierce assay with serum albumin as a standard.

Electrophoretic mobility shift assay. Oligonucleotide probes (Life Technologies Inc., Rockville, Maryland, USA) containing the following HIF- $1 \alpha$ binding sites were used: forward, TGCATACGTGGGCTTCC; reverse, ACGTATTCACCCGAAGGT.

Radioactive oligonucleotides were generated by $5^{\prime}$ end labeling of the sense strand with $\left[\gamma^{32}\right.$ P]ATP (ICN Biomedicals Inc., Costa Mesa, California, USA) using T4 polynucleotide kinase (New England Biolabs Inc., Beverly, Massachusetts, USA), annealing to an excess of antisense strand. The binding reactions were done in a volume of $20 \mu \mathrm{l}$ containing $5 \mu \mathrm{g}$ of nuclear extracts and $0.1 \mu \mathrm{g}$ of denatured calf thymus DNA in $10 \mathrm{mM}$ Tris- $\mathrm{HCl}$ (pH 7.5), $50 \mathrm{mM} \mathrm{KCl}, 50 \mathrm{mM} \mathrm{NaCl}, 1$ $\mathrm{mM} \mathrm{MgCl}_{2}, 1 \mathrm{mM}$ EDTA, $5 \mathrm{mM}$ DTT, and 5\% glycerol. After preincubation for 5 minutes on ice, $1 \mathrm{ng}$ of the radiolabeled probe $(10,000 \mathrm{cpm})$ was added. Incubation was continued for 10 minutes on ice and, in the case of the supershift experiment, an additional 20 minutes at on ice. For the competition experiments, competitor DNA was added 5 minutes prior to the addition of the labeled probe. The reaction mixture was then loaded onto a $5 \%$ nondenaturing polyacrylamide gel, which was pre-run at $185 \mathrm{~V}$ for 2 hours. Electrophoresis was carried out at $185 \mathrm{~V}$ in $0.3 \times$ Trisborate-EDTA $26.7 \mathrm{mM}$ boric acid and $1.5 \mathrm{mM}$ EDTA) at $4^{\circ} \mathrm{C}$. The gels were vacuum-dried and quantified with a PhosphorImager (Molecular Dynamics). All signals were within the linear range of quantitation.

Immunoblot assays for HIF-1 $\alpha$. Retinal nuclear extracts from nondiabetic, control-treated, and insulin-treated diabetic rats were prepared as previously described (33).
Forty $\mu \mathrm{g}$ of protein was fractionated on a $4-20 \%$ gradient gel by SDS-PAGE, followed by electroblotting onto a nylon membrane. After a 1-hour incubation in a blocking solution consisting of $20 \%$ IgG-free normal horse serum in PBS/Tween ( $0.5 \%$ Tween-20 [Sigma Chemical Co.] in PBS), the membrane was exposed to a 1:500 dilution of an anti-HIF-1 $\alpha$ antibody (mouse monoclonal; Sigma Chemical Co.) overnight at $4^{\circ} \mathrm{C}$. After washing in PBS supplemented with $1 \%$ Triton (Sigma Chemical Co.), the peroxidase-labeled secondary antibodies were added at a concentration of 1:10,000 (anti-mouse; Amersham Pharmacia Biotech, Piscataway, New Jersey, USA) for 40 minutes at room temperature. The proteins were visualized using the enhanced chemifluorescence technique (Amersham Pharmacia Biotech) and quantified with a PhosphorImager (Molecular Dynamics). All signals were within the linear range of quantitation.

Statistical analysis. All results are expressed as means \pm $\mathrm{SD}$. The data were compared by ANOVA. Differences were considered statistically significant when the $P$ values were less than 0.05 .

\section{Results}

Hyperglycemia and insulin upregulate VEGF via different signaling pathways. Insulin increased VEGF levels in RPE cell-conditioned media $(0.32 \mathrm{vs} .0 .89 \mathrm{pg} / \mu \mathrm{g}$ total protein, $n=4, P<0.001)$. Inhibition of p38 MAPK and PI 3-kinase suppressed the insulin-induced VEGF increases $(0.46$ and $0.49 \mathrm{pg} / \mu \mathrm{g}$ total protein, respectively; $n=4, P<0.001)$. Inhibition of $\mathrm{p} 42 / \mathrm{p} 44$ MAPK or PKC did not alter the insulin-induced VEGF increases $(0.8668$ and $0.8812 \mathrm{pg} / \mu \mathrm{g}$ total protein, respectively) (Figure 1, upper panel).

Hyperglycemia per se increased VEGF expression ( 0.32 vs. $0.81 \mathrm{pg} / \mu \mathrm{g}$ total protein, $n=4, P<0.001$ ). The osmotic control mannose had a relatively minor effect on VEGF expression ( 0.323 vs. $0.44 \mathrm{pg} / \mu \mathrm{g}$ total protein, $n=4, P<0.001)$. Inhibitors of the $\mathrm{p} 42 / \mathrm{p} 44$ MAPK, PKC, and P38 MAPK suppressed the hyperglycemia-induced VEGF increases $(0.34,0.35$, and $0.52 \mathrm{pg} / \mu \mathrm{g}$ total protein, respectively; $n=4, P<0.001$ ). PI 3-kinase inhibition did not alter the hyperglycemiainduced VEGF increases ( $0.81 \mathrm{vs.} 0.74 \mathrm{pg} / \mu \mathrm{g}$ total protein, $n=4, P<0.05$ ) (Figure 1, upper panel).

Insulin upregulates HIF-1 $\alpha$ through $p 38$ MAPK and PI 3-kinase, whereas hyperglycemia has no effect on HIF-1 $\alpha$ levels. Insulin alone increased HIF- $1 \alpha$ levels in vitro (HIF- $1 \alpha / \beta$-actin ratio 0.85 vs. 2.56 arbitrary units, $n=4, P<0.001$ ) (Figure 1, lower panel). Pretreatment of the cells with either the p38 MAPK or the PI 3-kinase inhibitor suppressed the insulin-induced HIF- $1 \alpha$ increases (1.967 and 1.513 respectively; $n=4$, $P<0.0001)$. Pretreatment with either the PKC or the p42/p44 MAPK inhibitors had no effect on HIF- $1 \alpha$ expression (2.538 and 2.414, respectively; $n=4$, $P>0.05)$. Hyperglycemia had no effect on HIF- $1 \alpha$ (HIF-1 $\alpha / \beta$-actin ratio increased from 0.87 to 1.005 , $0.99,0.987,0.99$, and 0.99 in cells treated, respectively, 
with the mannose control, high glucose plus p38 MAPK inhibitor, high glucose plus PI 3-kinase inhibitors, high glucose plus p42/p44 MAPK inhibitors, and high glucose plus PKC inhibitors).

Intensive insulin therapy normalizes blood glucose and body weight. The animals tolerated the implants well. No infections were observed at the insertion sites. Blood glucose levels normalized on the first day of insulin treatment but tended to drift a little higher by the fourth day (Figure 2a). Thereafter, the glucose levels dropped again and remained stable for the remainder of the experiment. The insulin implants normalized diabetic blood glucose levels (day 7), from $348.16 \pm 11 \mathrm{mg} / \mathrm{dl}$ in the untreated diabetic group and $363 \pm 8 \mathrm{mg} / \mathrm{dl}$ in the diabetic control implant-treated group, to $81.28 \pm 29 \mathrm{mg} / \mathrm{dl}$ in the insulin implant-treated group. As expected, the animals treated with the insulin implants gained $15.8 \%$ body weight compared with the animals receiving the control implants $(261.25 \pm 6.9 \mathrm{mg} / \mathrm{dl} \mathrm{vs.} 227 \pm 6.5 \mathrm{mg} / \mathrm{dl}$, $P<0.001, n=8$ per condition, day 7 ) (Figure $2 \mathrm{~b}$ ). Acute intensive insulin therapy increases retinal $V E G F m R N A$ levels. To investigate the effect of acute intensive insulin therapy on retinal VEGF mRNA levels, the RPA was performed (Figure 3a). Retinal VEGF mRNA levels were low but detectable in the nondiabetic rats. After normalization to the $18 \mathrm{~S}$ signal, VEGF mRNA levels were increased $94.4 \%$ following the induction of diabetes, as previously described ( 15.47 vs. $30.07, n=4-5$ per condition, $P<0.01$ vs. nondiabetic) (33). The VEGF mRNA levels were further increased by $70.0 \%$ in the insulin-treated animals $(51.1, n=3-4$ per condition, $P<0.005$ vs. diabetic with control implant) (Figure 3b).

Acute intensive insulin therapy increases the binding of HIF-1 $\alpha$ to the VEGF promoter. HIF- $1 \alpha$ binds to the hypoxia-responsive elements (HREs) in the VEGF promoter and upregulates gene transcription in vitro (34). The binding of retinal nuclear extracts from nondiabetic, controltreated diabetic, and insulin-treated diabetic rats to ${ }^{32} \mathrm{P}$-labeled oligonucleotides containing the HRE sequence was investigated (Figure 4a). Nuclear extracts from diabetic rats treated with insulin implants exhibited greater binding to the labeled oligonucleotides, whereas nuclear extracts from diabetic rats treated with the control implants bound to a lower degree. Supershift assays confirmed that HIF- $1 \alpha$ binding is present, and the specificity of the reaction was confirmed via competition with unlabeled oligonucleotides (Figure 4a).

Acute intensive insulin therapy increases HIF-1 $\alpha$ nuclear protein levels in diabetic retinae. In vitro, the insulin-induced transcriptional upregulation of VEGF occurs largely through HIF- $1 \alpha$ (34). To investigate the effect of insulin treatment on HIF- $1 \alpha$ nuclear protein levels in the diabetic retina, the HIF- $1 \alpha$ retinal nuclear protein content of nondiabetic, control-treated, and insulin-treated diabetic rats was determined via Western blot (Figure $4, b$ and c). The HIF- $1 \alpha$ nuclear content in the retinae of diabetic rats increased upon the induction of the diabetes (HIF- $1 \alpha / \beta$-actin ratio from 0.86 to 1.51). Treatment with the $\mathrm{p} 38, \mathrm{p} 42 / \mathrm{p} 44 \mathrm{MAPK}$, and PI 3 -kinase inhibitors reduced the diabetes-induced upregulation of HIF- $1 \alpha(1.25,1.31$, and 1.15 arbitrary units, respectively; $n=4, P<0.001)$, whereas PKC inhibition did not $(1.49, n=4, P>0.05)$. The nuclear HIF-1 $\alpha$ protein levels in the diabetic rats with control implants were not significantly different from those of the diabetic rats $(1.51$ vs. $1.68, n=4, P<0.05)$ (Figure 5 , lower panel). Retinal HIF- $1 \alpha$ content increased significantly in the diabetic animals treated with the insulin implants (1.68 vs. $3.17, n=4, P<0.05$ ) (Figure
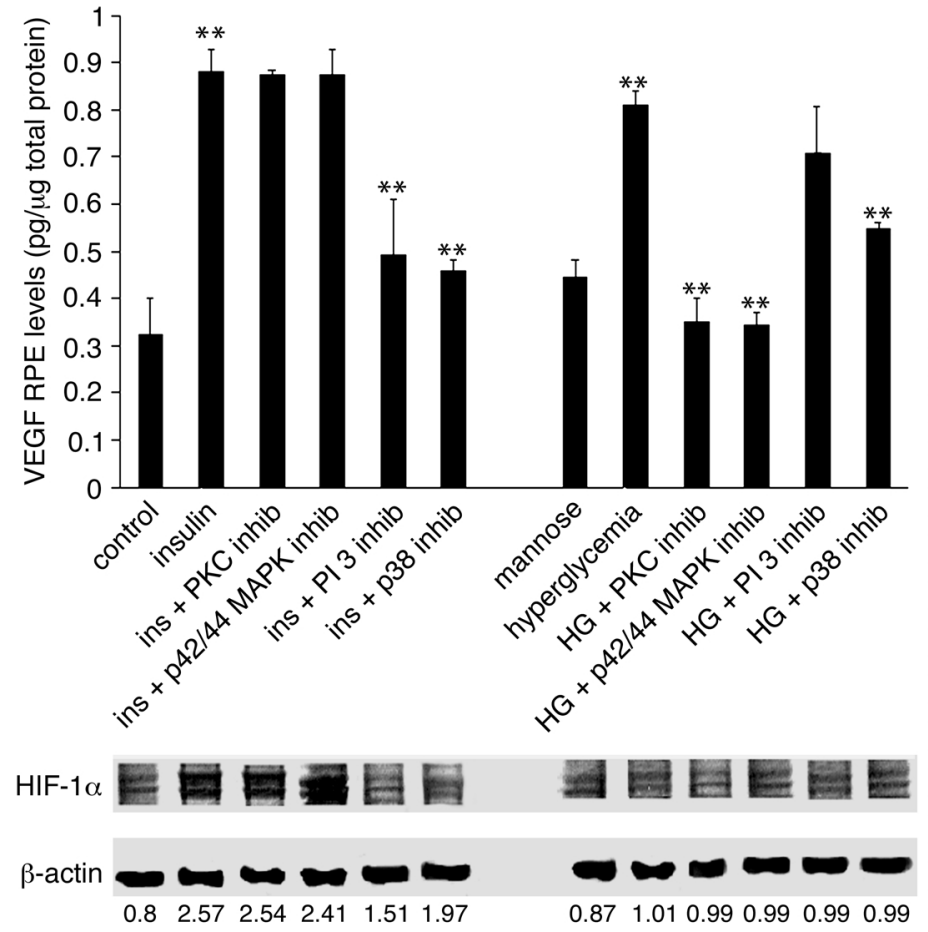

Figure 1

Upper panel: Conditioned media VEGF protein levels in RPE cells in vitro following exposure to high glucose and insulin (ins). Insulin increased VEGF protein levels (from 0.32 to $0.89 \mathrm{pg} / \mu \mathrm{g}$ total protein, $n=4, P<0.001$ ). Inhibition (inhib) of the 38 MAPK and PI 3-kinase suppressed the insulin-induced VEGF levels. Inhibition of $42 /$ p44 MAPK or PKC had no effect. Hyperglycemia (HG) increased VEGF levels in RPE-conditioned media in vitro. Inhibition of p42/p44 MAPK, PKC, and p38 MAPK suppressed the hyperglycemia-induced VEGF increases, whereas PI 3-kinase inhibition had no effect. Asterisks denote statistically significant results $\left({ }^{*} P<0.001\right)$. Lower panel: HIF- $1 \alpha$ protein levels in RPE cells in vitro following exposure to high glucose and insulin. Insulin increased HIF- $1 \alpha$ levels in vitro (HIF- $1 \alpha / \beta$-actin ratio 0.85 to $2.7, n=4, P<0.001$ ). Inhibition of p38 MAPK or PI 3-kinase suppressed the insulin-induced HIF-1 $\alpha$ increases (1.97 and 1.51, respectively; $n=4, P<0.001$ ), whereas inhibition of either PKC or $\mathrm{p} 42 / \mathrm{p} 44$ had no effect (2.54 and 2.41, respectively; $n=4$, $P>0.05)$. Hyperglycemia alone had no effect on HIF- $1 \alpha$ levels in vitro (HIF-1 $\alpha / \beta$-actin ratio increased from 0.87 to $1.01,0.99,0.99,0.99$, and 0.99 for the mannose control, high glucose + p38,PI 3-kinase, MAPK, and PKC inhibitor-treated cells respectively). Numbers represent the HIF- $1 \alpha / \beta$-actin ratio. 


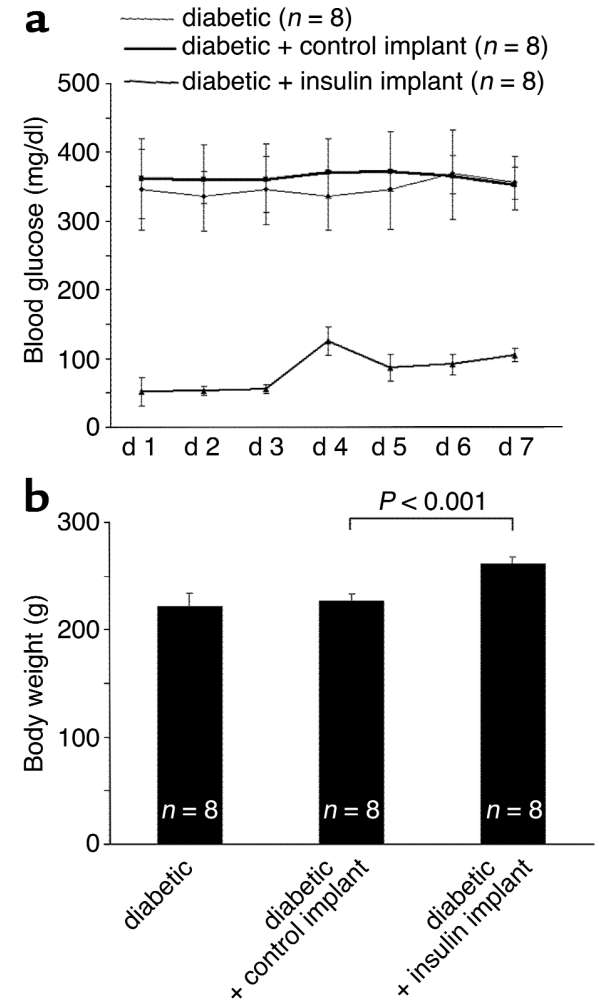

4, b and c). Treatment with p38 and PI 3-kinase inhibitors suppressed the insulin-induced increases (2.4 and 1.8, respectively; $n=4, P<0.001$ ). Treatment with the $\mathrm{p} 42 / \mathrm{p} 44$ MAPK inhibitors or the PKC inhibitors did not alter the insulin-induced nuclear HIF- $1 \alpha$ increases (2.8 and 3.1, respectively; $n=4$, $P>0.05)$ (Figure 5, lower panel).

Acute intensive insulin therapy increases retinal VEGF protein levels via PI 3-kinase and 738 MAPK. Retinal VEGF protein levels were increased from 0.59 to $1.3 \mathrm{pg} / \mu \mathrm{g}$ total retinal protein $(n=8$ per condition, $P<0.001)$ following the induction of diabetes (Figure 5, upper panel). Treatment with inhibitors of p38 MAPK and PI 3-kinase suppressed the diabetes-induced VEGF increases $(1.02 \mathrm{pg} / \mu \mathrm{g}$ total retinal protein $[n=8$, $P<0.005]$ and $0.71 \mathrm{pg} / \mu \mathrm{g}$ total retinal protein $[n=4$, $P<0.001]$, respectively), as did treatment with inhibitors of $\mathrm{p} 42 / \mathrm{p} 44 \mathrm{MAPK}$ and PKC $(0.85 \mathrm{pg} / \mathrm{\mu g}$ total retinal protein $[n=8, P<0.005]$ and $0.84 \mathrm{pg} / \mu \mathrm{g}$ of total retinal protein $[n=8, P<0.001]$, respectively). In the animals receiving acute intensive insulin therapy,

\section{Figure 3}

(a) RPA of the retinal VEGF mRNA levels. VEGF $120, V E_{164}$, and $18 \mathrm{~S}$ mRNA is shown. The figure shows protected fragments from nondiabetic animals, diabetic animals treated with control implants, and diabetic animals treated with insulin implants. (b) VEGF/18S mRNA signal ratio quantitation. After normalization to the $18 \mathrm{~S}$ signal, VEGF mRNA levels were increased $94.4 \%$ following the induction of diabetes ( $15.47 \pm 4.6$ to $30.07 \pm 6.7, n=4-5$ per condition, $P<0.01$ vs. nondiabetic animals), and another $70 \%$ in the insulin-treated animals $(51.1 \pm 10.4, n=3-5, P<0.005$ vs. nondiabetic animals).
VEGF protein levels were increased to $2.38 \mathrm{pg} / \mu \mathrm{g}$ total retinal protein $(n=8, P<0.001$ versus the diabetic animals with control implants). The insulin-induced VEGF increases were suppressed by the $\mathrm{p} 38$ MAPK and PI 3-kinase inhibitors $(1.72$ and $1.12 \mathrm{pg} / \mu \mathrm{g}$ total retinal protein, respectively; $n=8, P<0.001$ ). Treatment with the PKC and $\mathrm{p} 42 / \mathrm{p} 44$ MAPK inhibitors did not alter the insulin-induced VEGF increases (1.96 and 2.0 $\mathrm{pg} / \mu \mathrm{g}$ total retinal protein, respectively; $n=8, P<0.05)$ (Figure 5, upper panel).

Acute intensive insulin therapy exacerbates diabetic bloodretinal barrier breakdown. To investigate the pathophysiological consequences of acute intensive insulin therapy, the Evans blue assay was performed. Bloodretinal barrier breakdown was increased from $3.2 \mu \mathrm{l}$ plasma $\times$ g retinal dry weight ${ }^{-1} \times$ hour $^{-1}$ in nondiabetic rats to $7.5 \mu \mathrm{l}$ plasma $\times$ g retinal dry weight ${ }^{-1} \times$ hour $^{-1}$ upon the induction of diabetes $(n=12$ and 6 , respectively; $P<0.001)$. Rats treated with the PKC, $\mathrm{p} 42 / \mathrm{p} 44$,

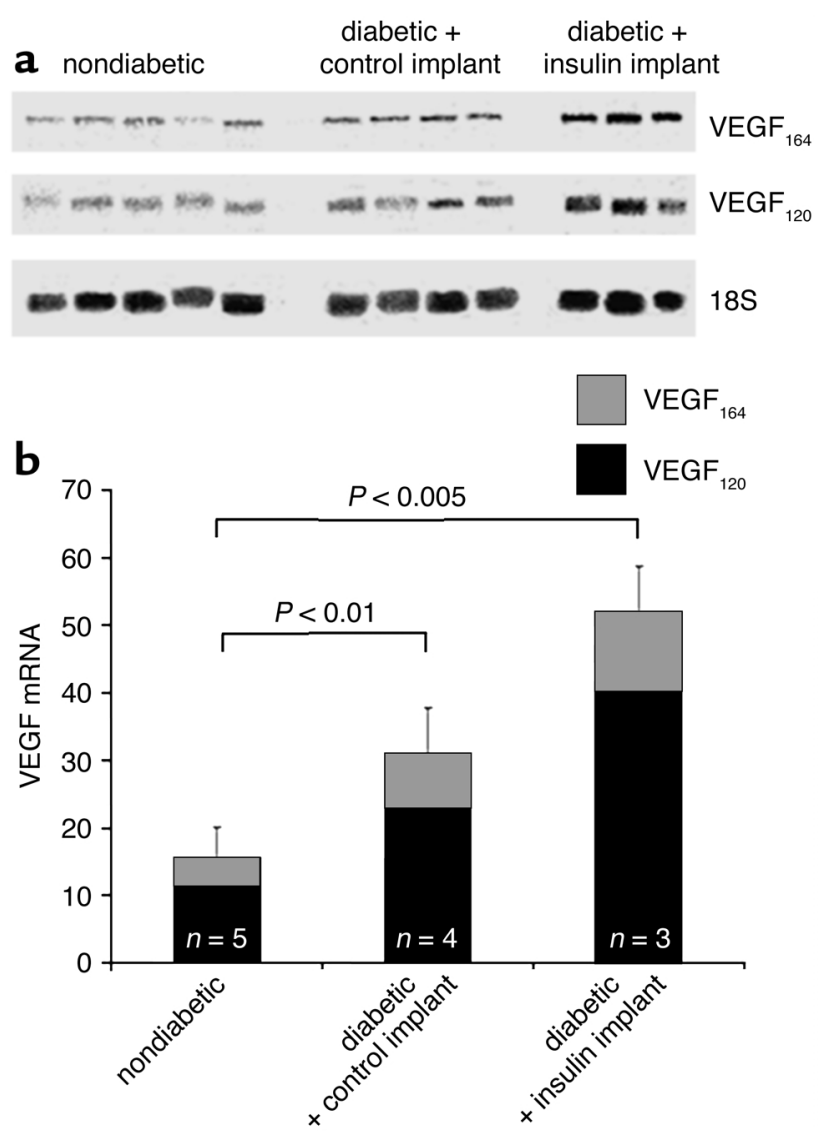


p38, and PI 3-kinase inhibitors showed a significant decrease in the diabetes-induced blood barrier breakdown $(4.37,5.03,5.4$, and $4.25 \mu \mathrm{l}$ plasma $\times \mathrm{g}$ retinal dry weight ${ }^{-1} \times$ hour $^{-1}$, respectively; $n=8, P>0.05$ ) (Figure 6). Blood-retinal barrier breakdown in the diabetic rats with control implants did not differ significantly from that in the diabetic animals without implants ( $n=12$ and 14, respectively; $P>0.05$ ) (Figure 6). However, a significant increase in blood-retinal barrier breakdown was observed in the rats treated with the insulin implants (from 7.4 to $13.8 \mu \mathrm{l}$ plasma $\times \mathrm{g}$ retinal dry weight ${ }^{-1} \times$ hour $^{-1}$, respectively; $n=14$, $P<0.001$ ) (Figure 6). The insulin-induced breakdown in the blood-retinal barrier was suppressed with inhibitors of p38 MAPK and PI 3-kinase (8.2 and 6.1 $\mu \mathrm{l}$ plasma $\times \mathrm{g}$ retinal dry weight ${ }^{-1} \times$ hour $^{-1}$, respectively; $n=8, P<0.001)$. Treatment with the PKC and the p42/p44 MAPK inhibitors failed to alter the insulininduced breakdown in the blood-retinal barrier $(11.75$ and $11.12 \mu \mathrm{l}$ plasma $\times$ g retinal dry weight ${ }^{-1} \times$ hour $^{-1}$, respectively; $n=8, P>0.05$ ) (Figure 6).

VEGF inhibition reverses the blood-retinal barrier breakdown increases associated with acute intensive insulin therapy. Previous work has shown that blood-retinal barrier breakdown associated with early diabetes is VEGF-dependent (33). To test the role of VEGF in the blood-retinal barrier increase induced by acute intensive insulin therapy, diabetic rats were treated with either VEGF TrapA 40 or the inactive isotype control Inactive IL-6R Trap (Figure 7). VEGF TrapA 40 reduced the insulin-induced increases in blood-retinal barrier breakdown by $50.3 \%$ (diabetic + insulin implant + VEGF TrapA 40 vs. Inactive IL-6R Trap, $n=14, P<0.001)$. Similarly, VEGF TrapA 40 reduced blood-retinal barrier breakdown in the diabetic animals with control implants by $42.3 \%$ (diabetic + control implant + VEGF TrapA 40 vs. Inactive IL-6R Trap, $n=8, P<0.005)$ (Figure 7 ).

\section{Figure 4}

(a) Nuclear HIF-1 $\alpha$ expression levels in the retinae of nondiabetic and diabetic rats treated with control and insulin implants. Following normalization to $\beta$-actin, the HIF- $1 \alpha$ protein levels in the diabetic animals increased $19.9 \%$ compared with the nondiabetic animals $(100 \pm 0.62$ vs. $119.6 \pm 4.26, n=5, P<0.05)$. The HIF- $1 \alpha$ content increased an additional $96.4 \%$ in the diabetic animals treated with the insulin implants $(235.04 \pm 15.37, n=5, P<0.05$ vs. control implants). (b) Western blot analysis of HIF- $1 \alpha$ retinal nuclear protein levels in nondiabetic and diabetic rats treated with control or insulin implants. Insulin treatment upregulates the HIF-1 $\alpha$ nuclear content in the diabetic rats. (c) Electrophoretic mobility shift assay for HIF- $1 \alpha$ in retinal nuclear extracts from nondiabetic rats and diabetic rats treated with control or insulin implants. The extracts were incubated with labeled HRE-containing oligonucleotides from the VEGF promoter. Lane 1, free probe; lane 2, nondiabetic rats; lane 3, diabetic rats; lanes 4 and 5 , insulin implant-treated rats; lane 6 , control implant-treated rats; lane 7, competition with the cold oligonucleotide; lanes 8 and 9 , incubation with the HIF- $1 \alpha$ antibody $(n=5$ retinae per lane for all). The markings on the left indicate the HIF-1 $\alpha$ complexes. The marking on the right identifies the supershifted bands following exposure to the HIF- $1 \alpha$ antibody.

\section{Discussion}

Diabetic retinopathy remains a leading cause of irreversible blindness in the developed world. Whereas the institution of strict glycemic control retards the development and progression of retinopathy over the long term, acute intensive insulin therapy initially results in a surprising and paradoxical deterioration, and confusion about treatment (35-38). The molecular mechanisms underlying this well-established observation remain unknown. In the current study, we demonstrate that the exacerbation of blood-retinal barrier breakdown is mediated by the upregulation of retinal VEGF expression in a relevant rat model of diabetic retinopathy. The insulin-induced transcriptional upregulation of the VEGF gene is mediated through the P38 MAPKand PI 3-kinase-dependent activation of the transcription factor HIF- $1 \alpha$ and is associated with the binding of HIF- $1 \alpha$ to the HRE(s) in the VEGF promoter. Additionally, we show that acute intensive insulin treatment
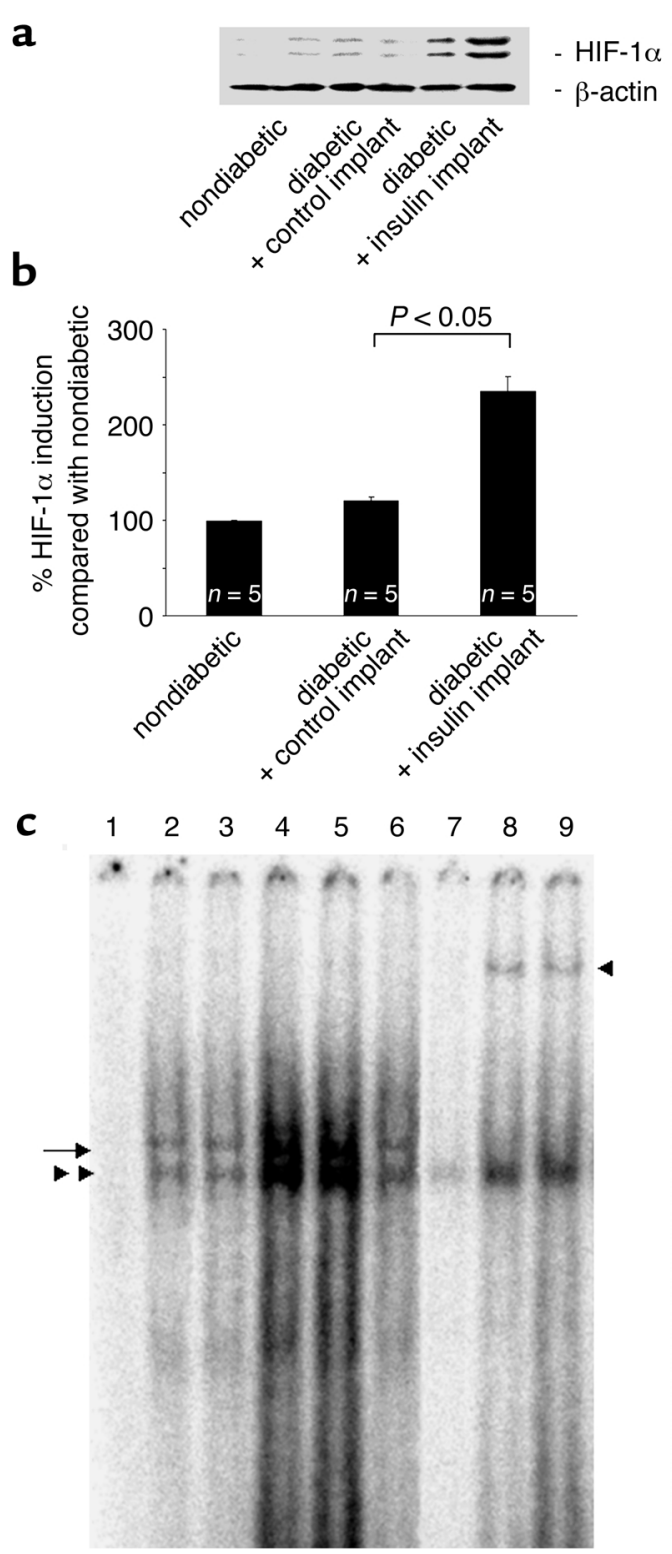

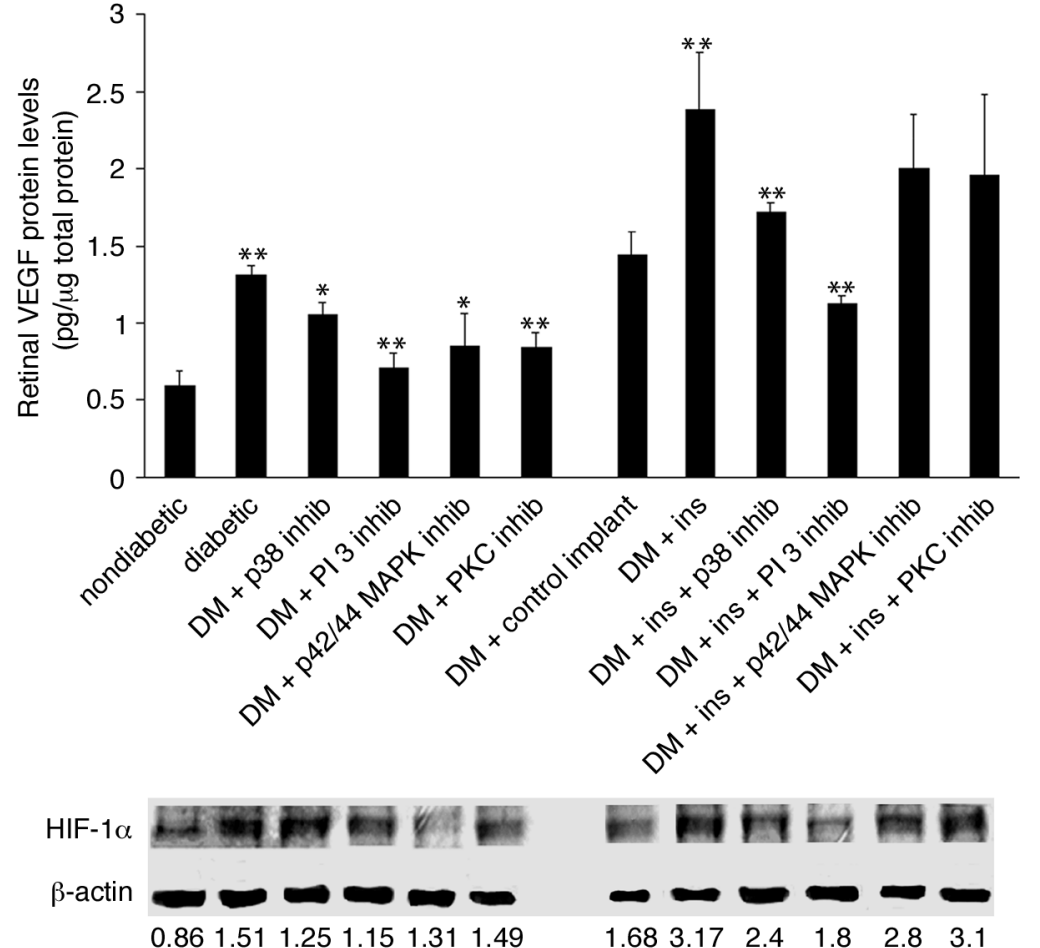

Figure 5

Upper panel: Retinal VEGF protein levels in diabetic (DM) animals with and without insulin and kinase inhibitors. Treatment with inhibitors of p38 MAPK, PI 3-kinase, $\mathrm{p} 42 / \mathrm{p} 44$, or PKC suppressed diabetes-induced upregulation of retinal VEGF protein levels (from 1.3 to $1.02,0.71,0.85$, and $0.84 \mathrm{pg} / \mathrm{mg}$ of total retinal protein, respectively; $n=8, P<0.001)$. Inhibition of P38 MAPK and PI 3-kinase suppressed insulin-induced upregulation of retinal VEGF levels in vivo (from 2.38 to 1.72 and $1.12 \mathrm{pg} / \mathrm{mg}$ total retinal protein, respectively; $n=8, P<0.001)$. Treatment with PKC or $\mathrm{p} 42 / \mathrm{p} 44$ MAPK inhibitors failed to suppress insulin-induced upregulation of retinal VEGF protein levels $(1.96$ and $2.0 \mathrm{pg} / \mathrm{mg}$ total retinal protein, respectively; $n=8, P>0.05)$. Asterisks denote statistically significant results $\left({ }^{*} P<0.005,{ }^{*} P<0.001\right)$. Lower panel: Retinal HIF- $1 \alpha$ protein levels in diabetic animals with and without insulin and kinase inhibitors. Treatment with p38 MAPK, p42/p44 MAPK, and PI 3-kinase inhibitors reduced the diabetesinduced upregulation of HIF- $1 \alpha$ protein levels (HIF- $1 \alpha / \beta$-actin ratio from 1.509 to 1.25 , 1.31 , and 1.15, respectively; $n=4, P<0.001$ ), whereas PKC inhibition did not have a significant effect (to $1.49, n=4, P>0.05$ ). Treatment with p38 MAPK and PI 3-kinase inhibitors suppressed insulin-induced upregulation of the retinal HIF-1 $\alpha$ levels (to 2.4 and 1.8, respectively; $n=4, P<0.001$ ). Treatment with either the $\mathrm{p} 42 / \mathrm{p} 44 \mathrm{MAPK}$ or the PKC inhibitors failed to alter levels (2.8 and 3.1, respectively; $n=4, P>0.05)$.

exacerbates diabetic blood-retinal barrier breakdown, an effect that is reversed by the administration of VEGF TrapA $\mathrm{A}_{40}$, a specific inhibitor of VEGF bioactivity, as well as inhibitors of p38 MAPK and PI 3-kinase.

Several theories have been proposed to explain the rapid progression of retinopathy that occurs upon the institution of intensive insulin therapy. One theory attributes it to a more severe initial disease state in the treated group rather than to the treatment itself or to the rapid lowering of the blood glucose levels. The consistent finding of retinopathy progression with acute intensive insulin therapy in several large randomized clinical trials suggests that this hypothesis is unlikely to be true (2-5). Whereas hyperglycemia is a risk factor for the progression of retinopathy, the twofold increase in the risk of retinopathy progression and the threefold increase in the risk of visual impairment associated with the changeover from oral hypoglycemics to insulin suggest that the underlying mechanism is far more complex (9). A second hypothesis states that insulin decreases retinal blood flow, leading to retinal hypoxia and precapillary vasodilation, which leads to increased blood-retinal barrier breakdown and edema. A third theory states that insulin is atherogenic, mitogenic, and thrombogenic (39). The beneficial effect of long-term intensive insulin therapy on diabetic retinopathy argues against insulin directly reducing blood flow, since it could lead to hypoxia and an upregulation of HIF- $1 \alpha$ and $\operatorname{VEGF}(6,10)$.

The increased retinal VEGF mRNA levels observed following the institution of acute intensive insulin therapy are consistent with a direct upregulation of VEGF gene transcription via insulin. It was recently demonstrated that insulin upregulates VEGF in epithelial cells in vitro via the activation of the transcription factor HIF-1 $\alpha$, which binds to HREs in the VEGF promoter (34). In the current study, we found that intensive insulin therapy increases retinal HIF- $1 \alpha$ levels and promotes HIF- $1 \alpha$ translocation to the nucleus. The regulation of HIF- $1 \alpha$ has been best characterized in hypoxic conditions, and a body of evidence suggests that it is posttranscriptional $(22,40)$. Under normoxic conditions, HIF-1 $\alpha$ binds to the von Hippel-Lindau protein and thus is targeted to the proteasome for degradation. Hypoxia and hypoxia-mimicking agents, like cobalt chloride, increase HIF-1 $\alpha$ levels by disrupting its association with the von Hippel-Lindau protein and by impairing its degradation (41). Our conclusions regarding the involvement of HIF- $1 \alpha$ in the insulin response are based on (a) the increased presence of HIF- $1 \alpha$ in the nuclei of the retinae of insulin treatedanimals, (b) the enhanced binding of HIF-1 $\alpha$ to the HRE sequences from the native VEGF promoter in the retinal nuclear fraction of insulin-treated animals, (c) the immunodetection, via antibodies, of retinal HIF- $1 \alpha$ bound to labeled HRE, and (d) the parallel attenuating effect of p38 MAPK and PI 3-kinase inhibitors on insulin-induced retinal HIF-1 $\alpha$ and VEGF expression. Therefore, our data strongly suggest that insulin upregulates retinal VEGF transcriptionally, via HIF-1 $\alpha$, in diabetics receiving acute intensive insulin therapy.

It is not currently known how insulin increases HIF- $1 \alpha$ and whether it involves phosphorylation or the 


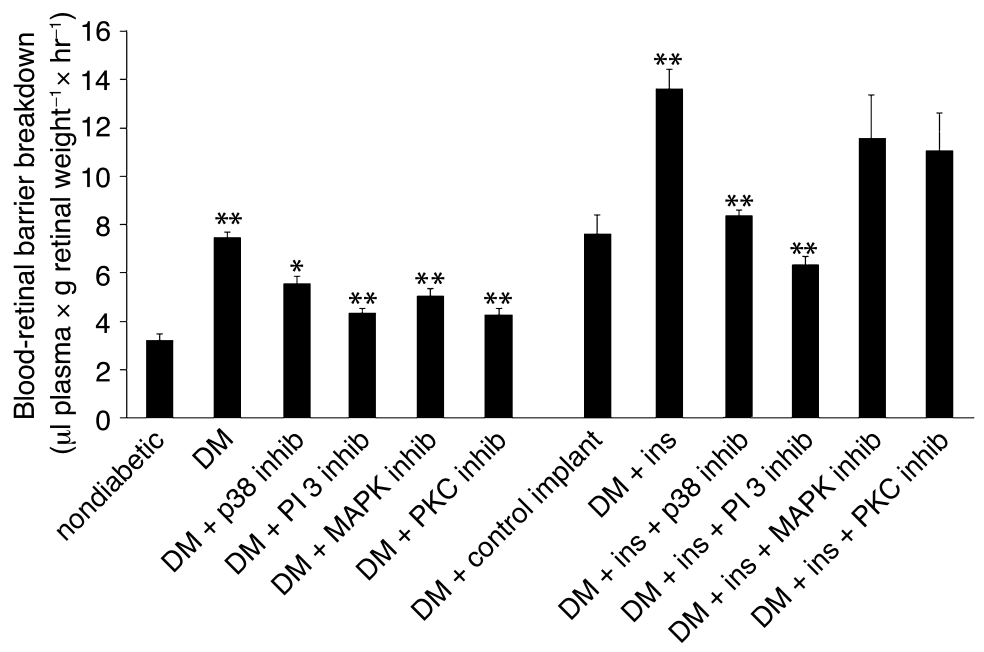

Figure 6

Blood-retinal barrier breakdown in diabetic animals treated with insulin and kinase inhibitors. The diabetes-associated increases in blood-retinal barrier breakdown were suppressed with inhibitors of PKC, p42/p44 MAPK, p38 MAPK, or PI 3-kinase ( 7.45 to $4.37,5.03,5.4$, and 4.25 $\mu$ l plasma $\times$ g retinal dry weight ${ }^{-1} \times$ hour $^{-1}$, respectively). The insulin-associated increases in blood-retinal barrier breakdown were suppressed with the inhibition of p38 MAPK and PI 3-kinase ( 8.2 and $6.1 \mu$ l plasma $\times$ g retinal dry weight ${ }^{-1} \times$ hour $^{-1}$, respectively; $n=8, P<0.001$ ), whereas inhibition of PKC or p42/p44 MAPK had no effect (to 11.75 and $11.12 \mu \mathrm{l}$ plasma $\times$ g retinal dry weight $^{-1} \times$ hour $^{-1}$, respectively; $n=8, P>0.5$ ).

activation of other factors, such as NF- $\kappa \mathrm{B}$. Insulin activates $\mathrm{PI} 3$-kinase, which in turn activates $\mathrm{PKB}$ and $\mathrm{PI}$ 3-kinase-dependent kinase (PDK) (42). We have found that the induction of HIF- $1 \alpha$ by insulin occurs through PI 3-kinase and p38 MAPK, and not p42/p44 MAPK or $\mathrm{PKC}$. This differential regulation is in agreement with Tacchini et al. (43), who demonstrated that HIF-1 $\alpha$ induction by HGF depends on c-jun kinase (JNK) and PI 3-kinase but not p42/p44 MAPK. The p42/p44 MAPK signaling pathway is activated by mitogens and is involved in the pathogenesis of diabetic retinopathy (44). As demonstrated in the present study, inhibition of the p42/p44 MAPK pathway reduces HIF- $1 \alpha$ levels and suppresses VEGF upregulation and blood barrier breakdown in diabetic animals, suggesting that it participates in these events in untreated diabetes. Nevertheless, it does not appear to mediate the insulininduced exacerbation of these phenomena. Additionally, although the activity of $\mathrm{p} 42 / \mathrm{p} 44 \mathrm{MAPK}$ is increased in diabetic animals compared with normal controls, it is not further increased in insulin-treated animals (data not shown). HIF-1 $\alpha$ has been reported to be phosphorylated by $\mathrm{p} 42 / \mathrm{p} 44 \mathrm{MAPK}$ and not by stress kinases in vitro (45), yet p42/p44 MAPK is not activated in cells exposed to hypoxia (43), indicating that it does not play a role in hypoxia-associated HIF-1 $\alpha$ phosphorylation in vivo. Similar results were seen following the inhibition of the PKC pathway, a known positive regulator of the MAPK p42/p44 pathway. Inhibition of the PKC pathway did not alter HIF-1 $\alpha$ and VEGF levels in insulin-treated animals, leading to the conclusion that PKC and $\mathrm{p} 42 / \mathrm{p} 44 \mathrm{MAPK}$ are not primary mediators of

\section{Figure 7}

VEGF inhibition reverses the blood-retinal barrier breakdown increases associated with acute intensive insulin therapy. VEGF TrapA 40 reduced blood-retinal barrier breakdown in the diabetic rats treated with control implants by $42.3 \%$ (diabetic + control implant + VEGF TrapA $_{40}$ vs. Inactive IL-6R Trap, $n=8, P<0.005$ ), and in the diabetic rats treated with the insulin implants by $50.3 \%$ (diabetic + insulin implant + VEGF TrapA 40 vs. IL-6R Trap, $n=14, P<0.001)$. the acute insulin-induced increases in VEGF and blood-retinal barrier breakdown.

Unlike the p42/p44 pathway, the JNK and p38 pathways are activated by proinflammatory cytokines and by diverse arrays of cellular stress (46). In our model of insulin-induced exacerbation of diabetic retinopathy, the JNK and p38 kinase are activated in the retinae of insulintreated rats (data not shown). It appears that these kinases play a major role in the stability and therefore the induction of HIF-1 $\alpha$. Mazure et al. have reported that hypoxia increases PI 3-kinase, but not MAPK, activity in vitro in a Ras-dependent manner, and that genetic or pharmacological inhibition of PI 3-kinase activity blocks HIF- $1 \alpha$ activity and VEGF induction (47). Jiang et al. have also shown that insulin- or EGF-induced PI 3-kinase activation specifically upregulates HIF-1 $\alpha$, and not HIF-1 $\beta$, in human cancer lines (40). Our finding that PI 3-kinase inhibitors attenuate HIF- $1 \alpha$ and VEGF upregulation suggests that PI 3-kinase indeed regulates the levels of HIF- $1 \alpha$ upon acute insulin administration.

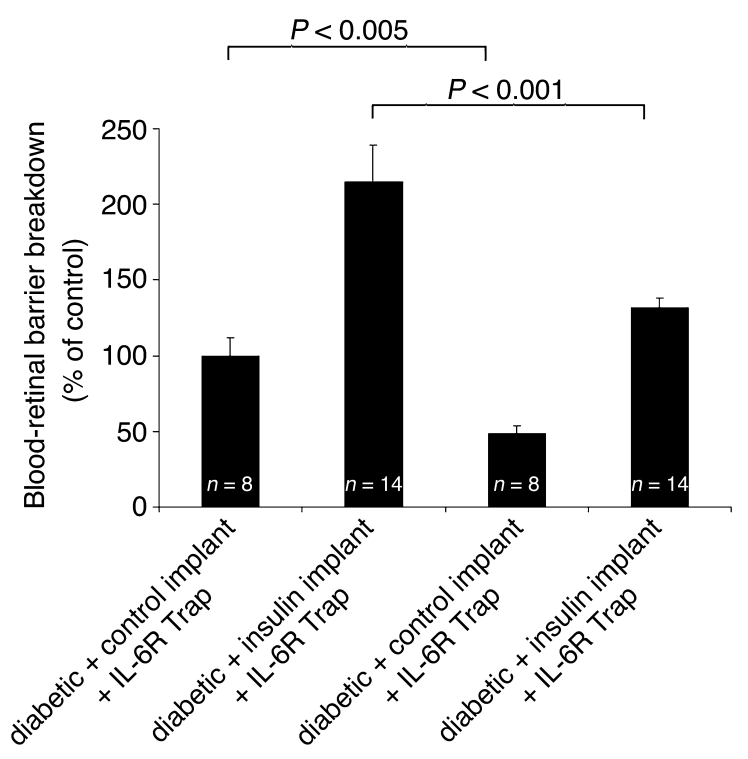


From these data, we conclude that the hyperglycemiainduced upregulation of VEGF differs from the insulin-induced upregulation of VEGF. Whereas mitogen-activated kinases, such as p42/p44 MAPK and $\mathrm{PKC}$, activated either serially or in parallel, mediate the hyperglycemia-associated increase of VEGF, they appear to have no effect on acute insulin-induced VEGF, which is mediated by p38 MAPK and PI 3-kinase, and most likely by JNK. Although the direct effects of insulin in HIF- $1 \alpha$ stabilization and activation in vitro argue against an indirect mechanism in vivo, we cannot exclude the possibility that an insulin-induced reduction in the blood flow and subsequent ischemia contributes to the upregulation of HIF- $1 \alpha$ in insulintreated animals.

IGF-1 also enhances VEGF expression in the retina. Vitreous IGF-1 levels are increased in diabetic retinopathy and other ischemic retinopathies (48). IGF-1 may act as both a direct angiogenic factor and an indirect factor via enhanced VEGF expression (49). However, insulin and IGF-1 increase VEGF mRNA levels via different mechanisms. Insulin activates PI 3-kinase, whereas IGF-1 activates MAPKs (42). It is unlikely that the IGF-1 receptor mediates the observed upregulation of VEGF in our model, since insulin binds to the IGF-1 receptor with a 100-fold lower affinity than IGF-1 does (50) and MAPK inhibitors do not block its downstream effects. Nevertheless, the contribution of IGF-1 to the acute insulin-induced VEGF upregulation observed in these studies should ultimately be determined via the targeted inhibition of IGF-1.

Two caveats concerning the current data require attention. Although VEGF mediates a critical sightthreatening pathology, blood-retinal barrier breakdown, it is likely only one of the factors contributing to the overall worsening of retinopathy. Microaneurysms and intraretinal microvascular abnormalities, although inducible by exogenous VEGF (51), may not be the direct result of the enhanced VEGF expression in disease. Furthermore, the current study identified a measurable increase in blood-retinal barrier breakdown within days of insulin treatment. However, in the clinic, fluorescein angiography does not readily detect increases in blood-retinal barrier breakdown immediately following the onset of intensive insulin therapy. We believe this dichotomy is due to the much greater sensitivity of the Evans blue method versus fluorescein angiography.

It is important to note that the acute insulin-induced VEGF increases appear to be eventually outweighed by the chronic beneficial effects of tight blood-glucose control. Retinal VEGF levels during the course of diabetes are determined by the dynamic interplay of a variety of stimuli. As diabetes progresses, long-term hyperglycemia results in oxidative stress and the formation of advanced glycation end products (AGEs), potent inducers of retinal VEGF gene expression $(52,53)$. Aggressive long-term insulin therapy reduces oxidative stress and AGE levels, thereby suppressing an important pathway in the induction of VEGF. We hypothe- size that these beneficial events eventually supersede the detrimental effects of acute intensive insulin therapy on VEGF gene expression.

In summary, we conclude that acute intensive insulin therapy results in the transcriptional activation of VEGF via p38 MAPK, PI 3-kinase, and HIF-1 $\alpha$, producing a paradoxical worsening of diabetic blood-retinal barrier breakdown. As a result, these molecules are appealing therapeutic targets for the treatment of diabetic retinopathy, especially in patients beginning intensive insulin therapy.

\section{Acknowledgments}

This work was supported by the Roberta W. Siegel Fund (A.P. Adamis), the Foundation Fighting Blindness (V. Poulaki), NIH EY12611 and EY11627 (A.P. Adamis), the Juvenile Diabetes Foundation (A.P. Adamis and A.M. Joussen), the Falk Foundation (A.P. Adamis), and the Iaccoca Foundation (A.P. Adamis).

1. 1993. The effect of intensive treatment of diabetes on the development and progression of long-term complications in insulin-dependent diabetes mellitus. The Diabetes Control and Complications Trial Research Group. N. Engl. J. Med. 329:977-986.

2. Brinchmann-Hansen, O.K., Dahl-Jorgensen, K., Sandvik, L., and Hanssen, K.F. 1992. Blood glucose concentrations and progression of diabetic retinopathy: the seven year results of the Oslo study. BMJ. 304:19-22.

3. Agardh, C.D., Eckert, B., and Agardh, E. 1992. Irreversible progression of severe retinopathy in young type I insulin-dependent diabetes mellitus patients after improved metabolic control. J. Diabetes Complications. 6:96-100.

4. Moskalets, E., Galstyan, G., Starostina, E., Antsiferov, M., and Chantelau, E. 1994. Association of blindness to intensification of glycemic control in insulin-dependent diabetes mellitus. J. Diabetes Complications. 8:45-50.

5.1995. The effect of intensive diabetes treatment on the progression of diabetic retinopathy in insulin-dependent diabetes mellitus. The Diabetes Control and Complications Trial. Arch. Ophthalmol. 113:36-51.

6. Reichard, P., Nilsson, B.Y., and Rosenqvist, U. 1993. The effect of longterm intensified insulin treatment on the development of microvascular complications of diabetes mellitus. N. Engl. J. Med. 329:304-309.

7. Roysarkar, T.K., Gupta, A., Dash, R.J., and Dogra, M.R. 1993. Effect of insulin therapy on progression of retinopathy in noninsulin-dependent diabetes mellitus. Am. J. Ophthalmol. 115:569-574.

8. Henricsson, M., Janzon, L., and Groop, L. 1995. Progression of retinopathy after change of treatment from oral antihyperglycemic agents to insulin in patients with NIDDM. Diabetes Care. 18:1571-1576.

9. Henricsson, M., Nilsson, A., Janzon, L., and Groop, L. 1997. The effect of glycaemic control and the introduction of insulin therapy on retinopathy in non-insulin-dependent diabetes mellitus. Diabet. Med. 14:123-131.

10. 1998. Intensive blood-glucose control with sulphonylureas or insulin compared with conventional treatment and risk of complications in patients with type 2 diabetes (UKPDS 33). UK Prospective Diabetes Study (UKPDS) Group. Lancet. 352:837-853.

11. Senger, D.R., et al. 1983. Tumor cells secrete a vascular permeability factor that promotes accumulation of ascites fluid. Science. 219:983-985.

12. Ferrara, N., Houck, K., Jakeman, L., and Leung, D.W. 1992. Molecular and biological properties of the vascular endothelial growth factor family of proteins. Endocr. Rev. 13:18-32.

13. Aiello, L.P., et al. 1994. Vascular endothelial growth factor in ocular fluid of patients with diabetic retinopathy and other retinal disorders. N. Engl. J. Med. 331:1480-1487.

14. Aiello, L.P., et al. 1995. Suppression of retinal neovascularization in vivo by inhibition of vascular endothelial growth factor (VEGF) using soluble VEGF-receptor chimeric proteins. Proc. Natl. Acad. Sci. USA. 92:10457-10461.

15. Adamis, A.P., et al. 1994. Increased vascular endothelial growth factor levels in the vitreous of eyes with proliferative diabetic retinopathy. Am. J. Ophthalmol. 118:445-450.

16. Malecaze, F., et al. 1994. Detection of vascular endothelial growth factor messenger RNA and vascular endothelial growth factor-like activity in proliferative diabetic retinopathy. Arch. Ophthalmol. 112:1476-1482.

17. Murata, T., et al. 1995. Vascular endothelial growth factor plays a role in hyperpermeability of diabetic retinal vessels. Ophthalmic Res. 27:48-52. 
18. Adamis, A.P., et al. 1996. Inhibition of vascular endothelial growth factor prevents retinal ischemia-associated iris neovascularization in a nonhuman primate. Arch. Ophthalmol. 114:66-71.

19. Kahn, C.R. 1994. Banting Lecture. Insulin action, diabetogenes, and the cause of type II diabetes. Diabetes. 43:1066-1084

20. Cheatham, B., and Kahn, C.R. 1995. Insulin action and the insulin signaling network. Endocr. Rev. 16:117-142.

21. Pollenz, R.S., Sullivan, H.R., Holmes, J., Necela, B., and Peterson, R.E. 1996. Isolation and expression of cDNAs from rainbow trout (Oncorhynchus mykiss) that encode two novel basic helix-loopHelix/PER-ARNT-SIM (bHLH/PAS) proteins with distinct functions in the presence of the aryl hydrocarbon receptor. Evidence for alternative mRNA splicing and dominant negative activity in the bHLH/PAS family. J. Biol. Chem. 271:30886-30896.

22. Wang, G.L., Jiang, B.H., Rue, E.A., and Semenza, G.L. 1995. Hypoxiainducible factor 1 is a basic-helix-loop-helix-PAS heterodimer regulated by cellular O2 tension. Proc. Natl. Acad. Sci. USA. 92:5510-5514.

23. Guillemin, K., and Krasnow, M.A. 1997. The hypoxic response: huffing and HIFing. Cell. 89:9-12.

24. Ghiso, N., Rohan, R.M., Amano, S., Garland, R., and Adamis, A.P. 1999. Suppression of hypoxia-associated vascular endothelial growth factor gene expression by nitric oxide via cGMP. Invest. Ophthalmol. Vis. Sci. 40:1033-1039.

25. Brunn, G.J., et al. 1996. Direct inhibition of the signaling functions of the mammalian target of rapamycin by the phosphoinositide 3-kinase inhibitors, wortmannin and LY294002. EMBOJ. 15:5256-5267.

26. Duncia, J.V., et al. 1998. MEK inhibitors: the chemistry and biological activity of U0126, its analogs, and cyclization products. Bioorg. Med. Chem. Lett. 8:2839-2844.

27. Cocolakis, E., Lemay, S., Ali, S., and Lebrun, J.J. 2001. The p38 MAPK pathway is required for cell growth inhibition of human breast cancer cells in response to activin. J. Biol. Chem. 276:18430-18436.

28. Dieter, P., and Fitzke, E. 1991. RO 31-8220 and RO 31-7549 show improved selectivity for protein kinase $\mathrm{C}$ over staurosporine in macrophages. Biochem. Biophys. Res. Commun. 181:396-401.

29. Ron, D., Luo, J., and Mochly-Rosen, D. 1995. C2 region-derived peptides inhibit translocation and function of beta protein kinase $\mathrm{C}$ in vivo. J. Biol. Chem. 270:24180-24187.

30. Mitsiades, N., Poulaki, V., Leone, A., and Tsokos, M. 1999. Fas-mediated apoptosis in Ewing's sarcoma cell lines by metalloproteinase inhibitors. J. Natl. Cancer Inst. 91:1678-1684.

31. Rawson, R.A. 1943. The binding of T-1824 and structurally related diazo dyes by plasma proteins. Am. J. Physiol. 138:708-717.

32. Xu, Q., Qaum, T., and Adamis, A.P. 2001. Sensitive blood-retinal barrier breakdown quantitation using Evans blue. Invest. Ophthalmol. Vis. Sci. 42:789-794.

33. Qaum, T., et al. 2001. VEGF-initiated blood-retinal barrier breakdown in early diabetes. Invest. Ophthalmol. Vis. Sci. 42:2408-2413.

34. Zelzer, E., et al. 1998. Insulin induces transcription of target genes through the hypoxia-inducible factor HIF-1alpha/ARNT. EMBO J. 17:5085-5094.

35. Brinchmann-Hansen, O.K., Dahl-Jorgensen, K.F., Hanssen, K.F., and Sandvik, L. 1985. Effects of intensified insulin treatment on various lesions of diabetic retinopathy. Am. J. Ophthalmol. 100:644-653.

36. Dahl-Jorgensen, K., Brinchmann-Hansen, O.K., Hanssen, K.F., Sandvik, L., and Aagenaes, O. 1985. Rapid tightening of blood glucose control leads to transient deterioration of retinopathy in insulin dependent diabetes mellitus: the Oslo study. Br. Med. J. (Clin. Res. Ed.) 290:811-815.

37. Lauritzen, T., Frost-Larsen, K., Larsen, H.W., and Decker, T. 1983. Effect of 1 year of near-normal blood glucose levels on retinopathy in insulindependent diabetics. Lancet. 1:200-204.

38. Puklin, J.E., Tamborlane, W.V., Felig, P., Genel, M., and Sherwin, R.S 1982. Influence of long-term insulin infusion pump treatment of type I diabetes on diabetic retinopathy. Ophthalmology. 89:735-747.

39. Savage, S., Estacio, R.O., Jeffers, B., and Schrier, R.W. 1997. Increased complications in noninsulin-dependent diabetic patients treated with insulin versus oral hypoglycemic agents: a population study. Proc. Assoc. Am. Physicians. 109:181-189.

40. Jiang, B.H., Semenza, G.L., Bauer, C., and Marti, H.H. 1996. Hypoxiainducible factor 1 levels vary exponentially over a physiologically relevant range of $\mathrm{O} 2$ tension. Am. J. Physiol. 271:C1172-C1180.

41. Huang, L.E., Arany, Z., Livingston, D.M., and Bunn, H.F. 1996. Activation of hypoxia-inducible transcription factor depends primarily upon redoxsensitive stabilization of its alpha subunit. J. Biol. Chem. 271:32253-32259.

42. Conejo, R., and Lorenzo, M. 2001. Insulin signalling leading to proliferation, survival and membrane ruffling in C2C12 myoblasts. J. Cell. Physiol. 187:96-108.

43. Tacchini, L., Dansi, P., Matteucci, E., and Desiderio, M.A. 2001. Hepatocyte growth factor signalling stimulates hypoxia inducible factor-1 (HIF1) activity in HepG2 hepatoma cells. Carcinogenesis. 22:1363-1371.

44. Joussen, A.M., et al. 2002. Suppression of diabetic retinopathy with angiopoietin-1. Am. J. Pathol. In press.

45. Richard, D.E., Berra, E., Gothie, E., Roux, D., and Pouyssegur, J. 1999. p42/p44 mitogen-activated protein kinases phosphorylate hypoxiainducible factor 1alpha (HIF-1alpha) and enhance the transcriptional activity of HIF-1. J. Biol. Chem. 274:32631-32637.

46. Mendelson, K.G., Contois, L.R., Tevosian, S.G., Davis, R.J., and Paulson, K.E. 1996. Independent regulation of JNK/p38 mitogen-activated protein kinases by metabolic oxidative stress in the liver. Proc. Natl. Acad. Sci. USA. 93:12908-12913.

47. Mazure, N.M., Chen, E.Y., Laderoute, K.R., and Giaccia, A.J. 1997. Induction of vascular endothelial growth factor by hypoxia is modulated by a phosphatidylinositol 3-kinase/Akt signaling pathway in Ha-ras-transformed cells through a hypoxia inducible factor- 1 transcriptional element. Blood. 90:3322-3331.

48. Grant, M., Russell, B., Fitzgerald, C., and Merimee, T.J. 1986. Insulin-like growth factors in vitreous. Studies in control and diabetic subjects with neovascularization. Diabetes. 35:416-420.

49. Punglia, R.S., et al. 1997. Regulation of vascular endothelial growth factor expression by insulin-like growth factor I. Diabetes. 46:1619-1626

50. Miele, C., Rochford, J.J., Filippa, N., Giorgetti-Peraldi, S., and Van Obberghen, E. 2000. Insulin and insulin-like growth factor-I induce vascular endothelial growth factor mRNA expression via different signaling pathways. J. Biol. Chem. 275:21695-21702.

51. Tolentino, M.J., et al. 1996. Intravitreous injections of vascular endothelial growth factor produce retinal ischemia and microangiopathy in an adult primate. Ophthalmology. 103:1820-1828.

52. Lu, M., et al. 1998. Advanced glycation end products increase retinal vascular endothelial growth factor expression. J. Clin. Invest. 101:1219-1224.

53. Kuroki, M., et al. 1996. Reactive oxygen intermediates increase vascular endothelial growth factor expression in vitro and in vivo. J. Clin. Invest. 98:166-175. 